\title{
CHINESE METHODS OF INFANT FEEDING AND NURSING
}

BY

\author{
B. S. PLATT and S. Y. GIN
}

(From the Department of Medicine, Henry Lester Institute of Medical

Research, Shanghai, China)

In any attempt to improve the dietary of a community, it is preferable to evolve from existing practices rather than indiscriminately to substitute foreign ones. It is obvious, then, that these indigenous practices must be known and preferably understood. Mere descriptions alone are often of interest, but their interest and value are enhanced when, as frequently is the case, domestic economies are found on examination to have a sound basis in terms of presentday scientific knowledge.

In relation to infant-feeding problems in China, a general account has been given (Platt, 1936) ; in an appendix to this account, it was indicated that the study was being developed along three main lines : (a) a survey of native methods ; (b) a critical examination of these in the ward with the aid of laboratory methods; and (c) the translation of the laboratory findings into practice in a typical community. The present paper is a contribution to the first part of this investigation.

The scope of the enquiries is given in the appendix referred to above. The method of enquiry was to take histories from mothers who were attending infant welfare clinics in a native part of Greater Shanghai-for the most part a poor district. The population was drawn from all parts of China, and most of the inhabitants had been in contact with their native place sufficiently recently to retain the habits characteristic of that place. The relationship of the investigators was such that there was no reason to doubt the authenticity of the data presented.

For a sample of 387 subjects, the distribution according to their native province is given in the following table :

\begin{tabular}{|c|c|c|c|c|c|c|c|}
\hline \multicolumn{5}{|l|}{ PROVINCE } & \multicolumn{2}{|c|}{ NUMBER } & OF SUBJECTS \\
\hline KiangSU & .. & $\ldots$ & $\cdots$ & $\ldots$ & . & . & 200 \\
\hline CheKIANG & .. & $\ldots$ & $\ldots$ & $\ldots$ & . & $\ldots$ & 111 \\
\hline KWANTUNG & & $\ldots$ & . & . & .. & $\ldots$ & 17 \\
\hline HUPEH & .. & . & . & . & .. & .. & 17 \\
\hline ANHWEI & .. & . & . & $\ldots$ & . & . & 9 \\
\hline KIANGSI & .. & . & . & . & . & $\ldots$ & 6 \\
\hline HOPEH & . & $\cdots$ & . & $\cdots$ & .. & $\ldots$ & 6 \\
\hline ShaNSI & .. & . & $\ldots$ & $\ldots$ & . & $\ldots$ & 6 \\
\hline SHANTUNG & .. & . & . & $\ldots$ & .. & $\ldots$ & 5 \\
\hline SHENSI & .. & $\ldots$ & .. & .. & .. & . & 3 \\
\hline SZECHUAN & $\cdots$ & $\ldots$ & $\ldots$ & $\ldots$ & $\ldots$ & $\ldots$ & 3 \\
\hline FUKIEN & .. & . & . & . & .. & . & 3 \\
\hline YUNNAN & . & $\cdots$ & $\ddot{3}$ & . & . & $\cdots$ & 1 \\
\hline
\end{tabular}


Almost all the subjects were drawn from areas in which rice is the staple article of diet.

It was possible to ascertain the economic status of 187 subjects, and a classification was made into ' good,' ' fair' and 'poor' according to the criteria shown in the following table :

TABLE 2

\begin{tabular}{lll|l|l}
\hline & & & $\begin{array}{c}\text { BASIS OF ASSESMENT : } \\
\text { INCOME LEVEL }- \text { IN SHANGHAI } \\
\text { DOLLARS PER MONTH }\end{array}$ & PERCENTAGE OF SAMPLE \\
\hline Good &.. &. & Above 40 & $26 \cdot 2$ \\
Fair &.. &.. & $20-40$ & $20 \cdot 3$ \\
Poor &.. &.. & 20 and below & $53 \cdot 5$ \\
\hline
\end{tabular}

At the time of investigation, 1 Shanghai dollar $=1 s .6 \mathrm{~d}$.

Breast feeding by the mother was met with in 379 instances in a total of 422 case histories. Of a group of thirty-six in which wet nurses were employed, twenty-six relied solely on milk from the wet nurse. In six cases imported milk powder was employed, and it was claimed by one mother that an infant had been brought up without the use of milk, rice starch powder being the basis of the feeding.

\section{Usual procedure}

A picture of the procedure in infant feeding by breast milk in China is afforded by the following description, which is based on the majority of the evidence examined in the investigation. Immediately after the baby is born and again a few hours later, a solution is given which contains some cathartic substance of native manufacture. This is intended to drive out of the body all of the 'heating' substances. Breast feeding is begun on the second day. A thin paste of rice flour or of starch cake (if the family can afford it), slightly sweetened, is given once or twice daily. In a few days' time, if the supply of milk is adequate, it is found that the child may refuse to take any additional food ; but commonly small amounts of rice flour continue to be fed. Breast feeding when established is irregular, the frequency being determined by the baby's cry. The infant is fed less frequently during the night, and some eight to ten feeds are usually given in the course of twenty-four hours. There is no accepted time for the duration of a feed, which is usually continued until the baby falls asleep.

When the infant attains the age of about five months, soft rice * is introduced into the diet-if the infant can be induced to take it. The amount given varies from two or three ounces twice daily; sufficient sugar being added to give a slightly sweet taste. After six months of age, some vegetable soup is mixed with the soft rice, which is gradually increased in amount until about

* A brief note of the various preparations of rice is given on p. 348 . 
three-quarters of the ordinary rice bowl is being taken, at each of two meals, daily.

When the baby is about eight months old, additions are made from the adult diet in the form of a little boiled rice mixed with vegetable soup. At a year, regular feedings of soft and boiled rice are instituted together with soups of various kinds (vegetable, meat or fish), egg, biscuit and oranges. In many places Chinese red 'dates' (Chinese jujubes) have been fed to babies with the belief, according to Chinese medical teaching, that they promote the circulation and increase the volume of the blood. The 'dates' (about a dozen for one meal) are cooked and mashed, or an extract is made from them. Whilst they may be eaten at any age, they are usually considered to be primarily a constituent of a weaning diet. By the time the infant has completed his first year of life, he is usually considered to be almost weaned ; but, as will be shown, the child may continue to have breast feeds for many more months.

The importance of good feeding of the mother and wet nurse for successful lactation is thoroughly appreciated by the Chinese. There are recognized rules as to the special food requirements, and the mother is expected to consume a definite number of eggs, chickens, quantities of fish, soup and so forth shortly after delivery. Even with the very poor, every effort is made to fulfil the requirements of tradition. Emphasis is laid on a sufficient supply of fluid, and when milk secretion is poor, drinks of many kinds are prescribed.

There are a number of preparations which are considered to have special virtues as lactagogues. Mashed lean pork is considered to be good; and a mixture of pork fat and red gram beans (Phaseolus mungo, L. var. subtrilobata, Fr. et Sav.) is sometimes used. Cuttle-fish (Sepia esculenta, Hoyle) is used in the form of a soup alone or together with chicken. Shrimps cooked with red Chinese wine or shrimps' heads in wine are recommended. The use of cooked sea-slugs (Stichopus japonicus, Selenka) has been noted. Rice wine is often associated with supposed galactagogues; it is taken together with wheat cakes and millet. Special sweet wine made from glutinous rice is sometimes given together with the larvae of blow-fly collected from faeces. A powder made from dead silkworms is made up into a mixture with old wine. The silkworms are those which have not proceeded to the cocoon stage; their bodies have not decayed, and they are collected as stiff white worms. Noodles (vermicelli) made of wheat with the addition of egg or chicken are commonly taken. Another preparation that is sometimes used is the 'milk' prepared from the soya bean with powdered walnut added.

\section{Wet nursing}

The importance of wet nursing is apparent, and in big cities especially there is a definite system in practice. The wet nurse usually comes in from country areas about two months after she has had her own baby. She may delay for six or seven months if her milk is abundant. Her own infant may be deposited at a foundling home, or she may arrange for a fellow-countrywoman to feed it along with her own baby for a sum of two or three dollars each month. She 
attaches herself to a shop in the city which is run as a general servants' agency. The proprietor supplies a baby in order to maintain the milk secretion. The wet nurse pays for room and board provided by the agent, and, if she succeeds in obtaining employment, she pays a fee of half her first month's wages to the agent, and the customer pays an amount to the agent of 80 per cent. of the wages. The employer is expected to pay two months' wages in advance to the wet nurse when she is engaged, and he agrees to pay a bonus of an extra month's wages after the child is weaned. She is expected to serve a probationary period of three days to a week in the home. After her wet nursing duties are completed in the one family, she may be taken on as a servant, she may seek further employment as a wet nurse, or she may return to her own home. It is considered desirable that the wet nurse should have certain qualities. She should be young, healthy, of pleasant disposition, and if possible of pleasing appearance. A primiparous woman is preferred. Her breast development should be ample, and attention is paid to the areola of the nipples, which should be black as an indication of the recent delivery of the nurse's own infant. It is recognized that the milk must be white and thick ; yellow milk, and bluish, thin milk is not good. A test employed is to drop milk on to the table ; the drop formed must be round and raised, and it should not be possible to blow it into smaller drops. A recognized method of determining the quality of milk is by weighing a sample on a special scale which is used for weighing gold ; one pan when full should weigh two 'chien' and eight 'li.' Another consideration recognized in the choice of a wet nurse is the behaviour of the baby, which should not cry if the milk is satisfactory.

\section{Mixed feeding}

If the infant's food requirements cannot be wholly met by human breast milk, the commonest method is to add rice flour or starch cake paste at feeds two or three times in the day. The amounts given approximately during the first two weeks are about $1 \mathrm{oz}$. each day ; this is doubled in the second month, and in the third as much as $4 \mathrm{oz}$. a day are given. According to the demands of the child the amounts are gradually increased until a maximum of one bowl of rice mixture (the consistency of paste, one bowl containing 240 c.c.) is given two or three times a day.

Three hundred and ninety case histories have been examined for foodstuffs which were taken in addition to breast milk in what can conveniently be called 'mixed feeding.' The foodstuffs and the frequency with which they occurred are shown in chart $I$.

The ages at which this mixed feeding commenced for these subjects are given in chart II.

In some of these cases (158) it was possible to get a sufficiently precise statement to be able to say that the foodstuffs had been given because of the insufficiency of the breast milk. If by 'complementary feeding' it is implied that additional food is being given at the end of each feed on account of insufficient milk, then these cases can be considered as being examples of true 
complementary feeding. The kinds of food used and the numbers of instances for each food are given in the accompanying chart (chart III).

The ages at which complementary feeding was introduced were ascertained for 152 infants. and the results are represented in chart IV.

Chart I

The distribution of mixed feeding in 390 cases

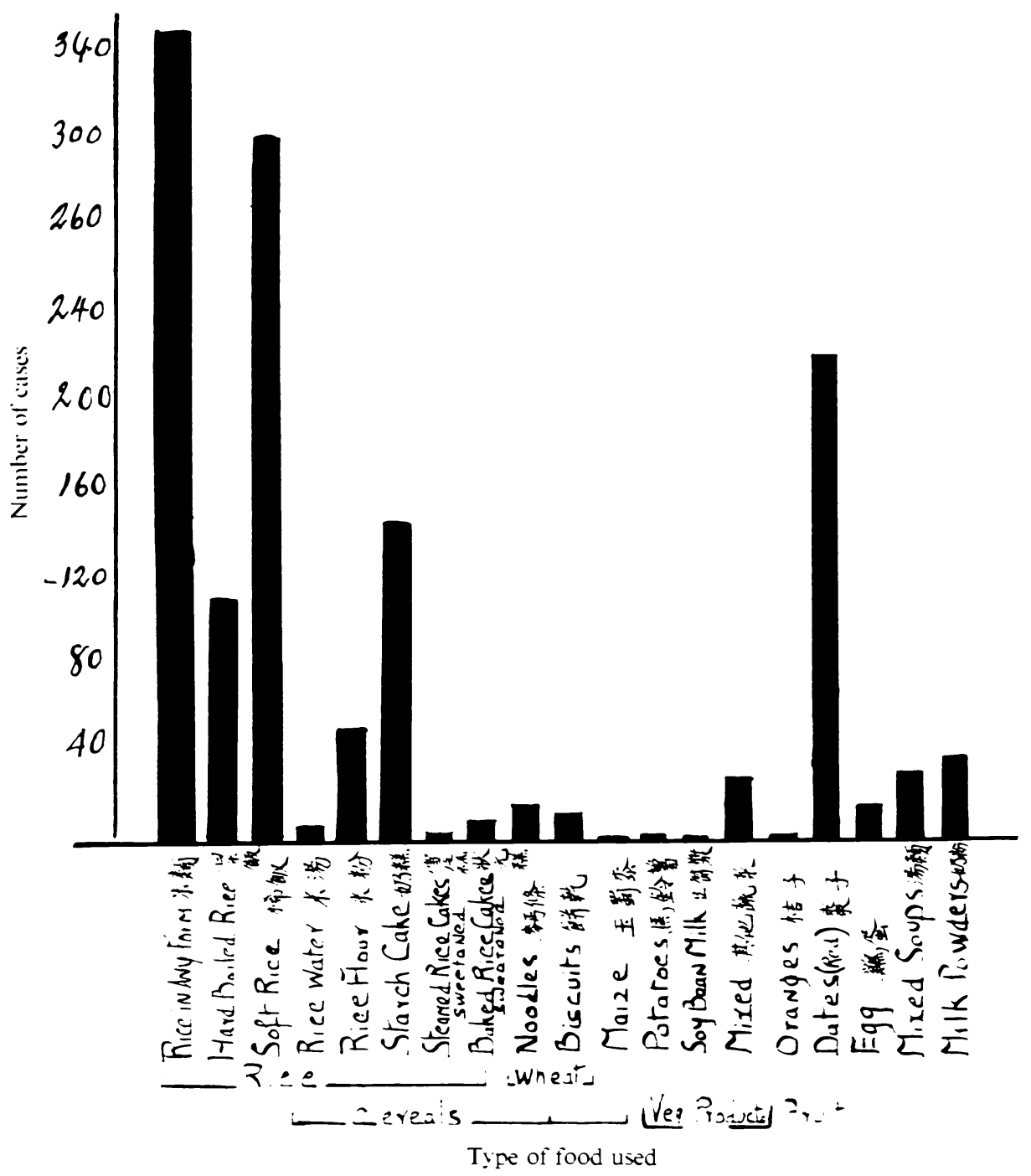

In nearly half the cases complementary feeding was initiated in the first month. especially during the first few days of life. This incidence appears to be accounted for by the practice of starting some additional feeding at birth, as described above. then deciding after a few days that the extra feeding must continue on account of inadequate supplies of breast milk. It is noteworthy. 
that starch cake was more commonly used in purely complementary feeding. Red 'dates,' it will be noticed, are not given as they appear to be considered peculiar to the weaning diet.

Some of the foodstuffs appearing in the foregoing charts may be described briefly. Soft rice (congee) is made of polished white rice simmered for one hour with six parts of water ; thus $125 \mathrm{gm}$. of rice with 725 c.c. of water will ultimately yield about two bowls of soft rice. The fluid separated off from the grain in this preparation is known as 'rice-water.' For the preparation of

\section{Chart II}

The distribution of ages at which mixed feeding began

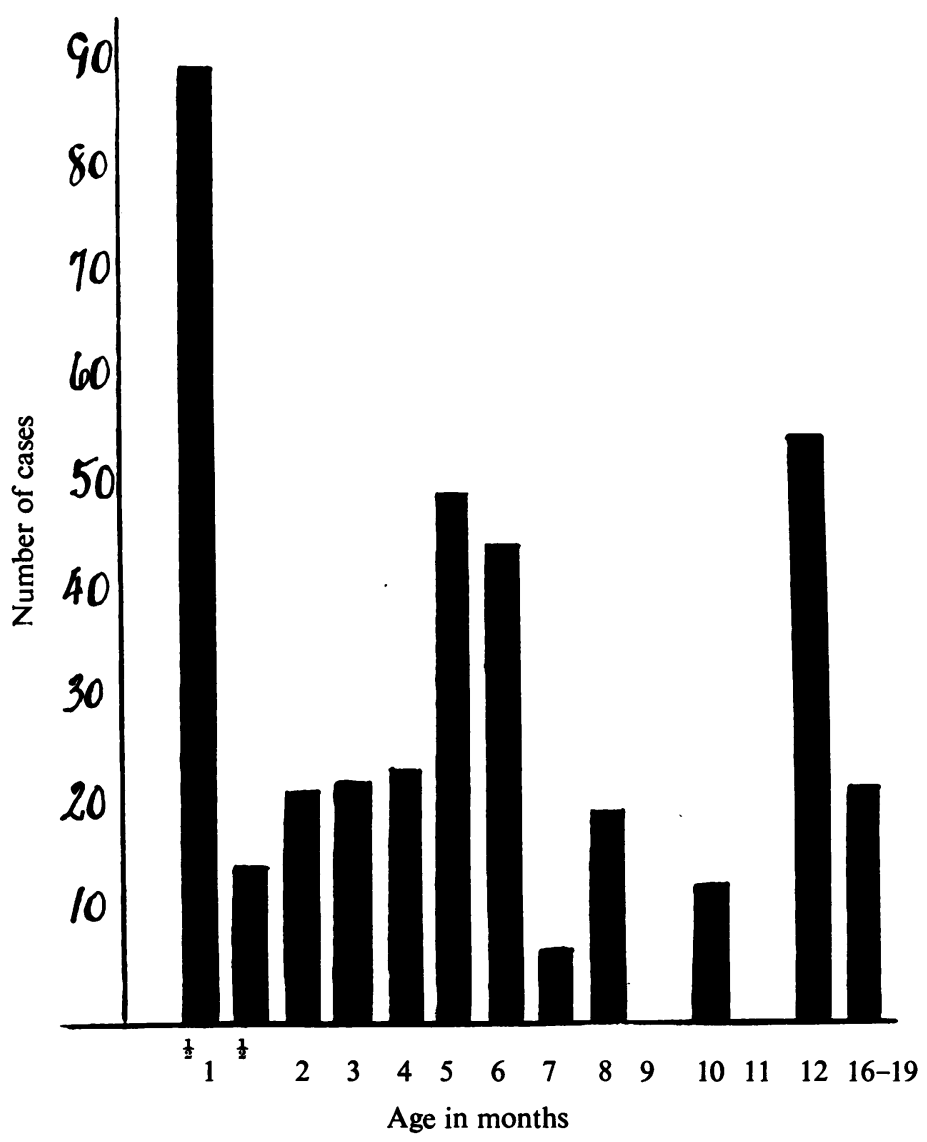

' rice-flour,' white, non-glutinous, polished rice is washed and ground in a Chinese stone handmill. The powder is dried, and can be kept for use. It is cooked by steaming with water and a little sugar in the rice-boiler of the native cooking-stove. For infant feeding, either so called 'early seasoned rice' or 'red rice,' i.e. unmilled rice having a pigmented pericarp, is preferred by some. ' Yellow rice,' a milled rice which has been stored for some months under moderate heat, is not considered good because it is ' rough' to swallow. Steamed rice cakes (sweetened) are made from finely sieved, polished, white rice flour steamed with additional sugar and then cut up into small pieces. 
Chart III

The distribution of 'additional ' foodstuffs in 158 cases

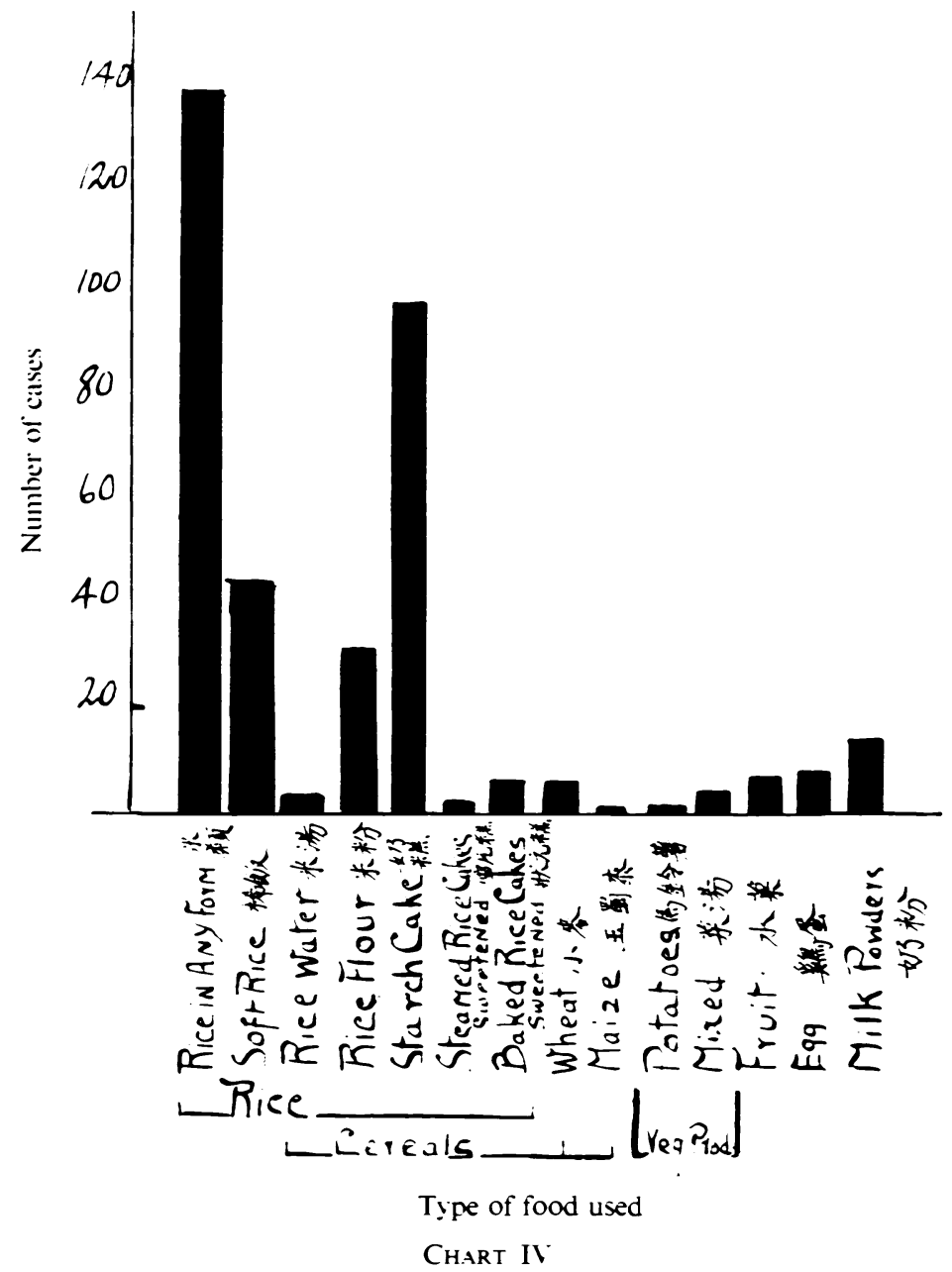


Baked rice cakes (sweetened) are made from roughly sieved, white, nonglutinous rice flour steamed, cut and then baked. Only a small amount of sugar is added. Ordinary starch cakes are made from rice flour, slightly steamed, but without the addition of sugar.

In addition to the points mentioned above in regard to breast feeding by the Chinese mother, the data in chart V show the ages at which breast feeding ceased in 398 cases.

\section{Chart V}

The distribution of ages at which breast feeding ceased in 398 cases

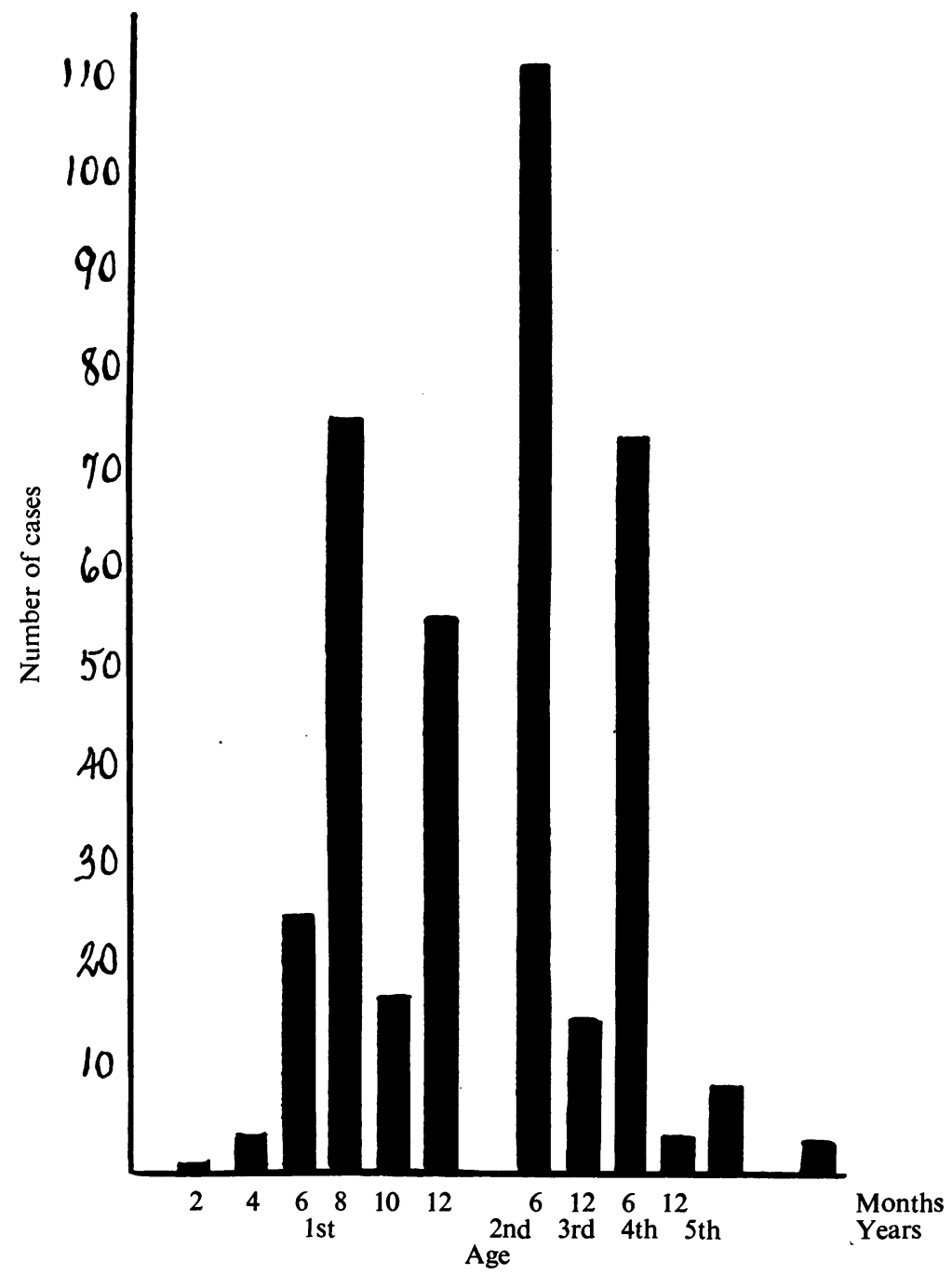

In nearly a third of the cases, breast feeding is discontinued by the end of the first year ; nearly half of all the cases continue into the second year ; a number continue until the end of the third year, and a few instances have been observed in which some feeding has continued until the end of the fourth and even fifth years. 


\section{Weaning}

In a series of 305 cases, the indications for weaning were investigated. The results are shown in the following table :

\section{TABLE 3}

\begin{tabular}{|c|c|c|c|c|}
\hline & \\
\hline \multicolumn{2}{|l|}{ REASON GIVEN FOR WEANING } & & & $\begin{array}{c}\text { NUMBEK OF } \\
153\end{array}$ \\
\hline Insufficient breast milk & 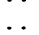 & .. & & \\
\hline 'Child is big' . & & & & 34 \\
\hline According to custom & & & & 23 \\
\hline Poor health of mother & .. & .. & .. & 19 \\
\hline Demands of employment & .. & .. & . & 17 \\
\hline Poor health of child .. & . & $\cdots$ & .. & 3 \\
\hline Child refuses to take .. & .. & .. & .. & \\
\hline Breast abscess ... .. & .. & .. & .. & 2 \\
\hline Fissured nipples & . & .. & . & 1 \\
\hline Uselessness of wet nurse & .. & 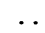 & 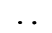 & 1 \\
\hline Doctor's advice & .. & .. & . & 1 \\
\hline
\end{tabular}

Enquiries showed that of 308 cases, 219 were weaned on to an adult diet. About half the remainder were fed largely on soft rice. In twenty-six cases milk powder was used. In only isolated instances was any addition of egg made, and only once was there a record of the use of soya bean milk.

\section{Discussion}

The feeding habits which have been described will be seen from table 1 to be mainly concerned with the natives of East-Central China. In general similar customs prevail in the predominantly rice-eating population of WestCentral and South China. In the North, the staple cereals are millets and wheat. Methods of feeding of young children in North China have been described recently by Guy (1936). She says that infants are fed exclusively on breast milk until the age of six months, when tastes of the family food are introduced; thus small amounts of soups made from turnip, cabbage or salted vegetable are fed along with a little gruel made from millet or rice and bits of steamed wheat bread, or one made from a mixture of corn flour and soya bean flour. Raw turnip is given to the child to nibble; often some hot sweet potato, and rarely eggs.

It is noteworthy that, as in the present series, soya bean 'milk' is never used in infant feeding; a hot weak solution sold in the streets of Peiping is taken by old people as a beverage. At a recent conference of nutrition experts in the Far East, it was recorded (Bandoeng Conference, 1937) that soya bean milk had little in common with mammalian milk beyond a white colour. A soft bean curd may, however, be used with advantage (Platt, 1936) in a mixture for weaning purposes.

Guy concludes that unless there is enough breast milk and until the child is able to feed without help, food is likely to be insufficient until about the eighteenth month. This is due not only to the expense and trouble involved in the preparation of special food, but also to a lack of patience at the inevitable slowness of the child. If, however, the child can be assured of a supply of $500-700$ c.c. of maternal milk in addition to its share of the family diet, it is believed that the difficulties of this weaning period will be overcome. 
King (1936) was told by a physician working in West China that there were many practices and customs which contributed to a high death-rate among Chinese infants. One of these was given as the feeding of meat masticated by the mother to children before they have teeth. This is said often to give rise to fatal convulsions in the infant. Pre-chewing of pap foods may be seen throughout China. It is known still to occur in other parts of the world-as, for example, in the Dutch East Indies, Indo-China, and parts of Africa. It was a custom in Europe, for, according to Still (1931), discussing conditions in the sixteenth century, "writer after writer had handed on the unwholesome advice of Avicenna (980-1037 A.D.) that the nurse before giving bread or other solid food to the infant should chew it thoroughly in her own mouth, and then spew it, or put it with her fingers, into the infant's mouth.'

Additions of preparations of cereals to the infant's diet has, of course, been common for centuries in Western countries (Garrison, 1923 ; and Still, 1931). This practice led to the introduction of special utensils for feeding, the evolution of which has been described by Still. In China, chopsticks and porcelain spoons and bowls such as are used by adults are employed in infant feeding. In other countries spoons are not always available, so that when additions of gruels are made some other method is adopted. A description from Nyasaland (1938) is of interest in this connexion : "The cupped hand is filled with gruel and attempts are made to empty the contents into the infant's mouth. Resistance is useless, the gruel flows down the nostrils and in the choking and spluttering which follows, a quantity is swallowed by the infant. This is repeated two or three times daily and sometimes at night.'

Whilst the use of rice in the parts of China investigated is determined by the fact that rice is the staple cereal, it is of interest to find that it has been recommended for use in infant feeding from time to time in the West. William Cadogan (1711-97) writes, "I would advise therefore that one half of Infants Diet be light thin Broth, with a little Bread or Rice boiled in them which last is not so acescent as any other kind of Meal or Flour. . . .' It has long been recognized (Hutchison and Mottram, 1936) that rice is a most readily and completely digestible cereal. Of the cereals examined by E. Mellanby (1937) for their effect on the growth of bones, rice is the one which gives rise to the least adverse effect on calcification. The protein of rice, whilst only present to the extent of 7 or 8 per cent., is generally considered to be of good biological value. The inclusion of rice in the diets of mothers feeding babies, and into the diets of the babies has, on the other hand, been considered to have a deleterious effect on deciduous teeth, and the mortality and morbidity of infants, according to the results of an investigation by Larsen, Jones and Pritchard (1934) in Hawaii.

The Chinese use rice in a powdered form-the pulverization of the grain being a matter of some importance in determining utilization (Platt, 1936). They have also appreciated the advantage of thorough cooking of the cereal, for the rice starch cake is heated and partially dextrinized in course of preparation.

The fact, however, that rice is introduced into the diet so frequently and 
at a very early age raises the question of digestibility of starch by the infant. There was a period in Europe after the general use of pap foods when breast feeding was insisted upon until the age of twelve months. More recently, feeds of starchy foods have been recommended to be introduced by some at six to eight months, and by others as early as the third or fourth month. One of the reasons given for not feeding starch during the first year was that the infant had no salivary enzymes capable of digesting the starch. There is, however, abundant evidence in the literature that there is ptyalin in the saliva of the infant and amylase in the pancreatic juice (Feldman, 1920; White House Conference, 1932-3). Whilst this is true, there is evidence that there is more ptyalin in strong than in weak infants, and that the amount of amylase increases markedly in older children. Furthermore, even when starch is properly prepared and well cooked, it is believed that the young infant cannot digest it completely, though it appears to be possible to develop gradually the power of digesting it fairly well when it is fed from an early age (White House Conference, 1932-3).

The problem of starch digestion has been recently discussed by ArmandDelille (1935). The results of the experiments of his assistants Bespaloff and Lestocquoy show that in infants under two months, amounts of 5-10 gm. of uncooked wheat flour fed with milk are not digested, and 5-10 gm. lots of fully cooked wheat flour are not absorbed ; from two to four months these amounts are partially absorbed, and after four months complete absorption may be obtained for both preparations fed at these levels. At this age, however, amounts of $15 \mathrm{gm}$. are incompletely digested. When the smaller amounts are fed daily for six to seven days, it appears that digestion becomes complete, and it is suggested that there is an adaptation taking place, probably in the nature of a progressive increase in the secretion of amylase. If pure wheat starch is used, it has been found possible to secure complete absorption of $30 \mathrm{gm}$. after feeding for fifteen days to a baby of three months.

From the present observations it appears that the Chinese have been feeding rice starch and flour in amounts similar to those found experimentally by the Frenchinvestigators to be digested by young infants.

It is interesting that in the history of paediatrics systems of wet nursing similar to those in present use in China have been employed. The test of the quality of milk depending on the behaviour of a drop is similar to the "fingernail test' used for centuries in Europe, and attributed to Soranus of Ephesus (98-117 A.D.). The accuracy of the Chinese gold balance is such that the specific gravity method is probably superior to those employed in early days in Europe.

The practice of irregularity of feeding both with regard to frequency and duration, the use of cathartics, and of worms, fish and wine extracts as lactagogues, have their counterpart in the history of infant management in Western countries. It should be emphasized that the Chinese are fully aware of the importance of adequate nutrition of the mother in pregnancy and throughout lactation.

The point was made at the beginning of this paper that a knowledge of 2 B 
existing customs and circumstances must form the basis of any improvements. Only a superficial acquaintance with conditions in China will show that the introduction of Western methods is impracticable, for there is little milk except human milk, dairy farming requires too much land to be a practical measure, and the Chinese cannot, in general, afford to buy imported preparations of cows' milk. It is not proposed to discuss further this question of making improvements, except to quote a recent comment from a study (Buck, 1938) of 38,256 farm families in twenty-two provinces in China, in which is given a figure of 156 deaths under one year of age per one thousand births (an estimate which is probably low): 'If, by some magic,' Buck writes, 'it suddenly became possible to eliminate the mortality from " preventable causes " of death, sober students might ponder long before utilizing that power. . . . It is perhaps fortunate that any improvement in mortality rates will, if it comes, come gradually, and may be accompanied by a corresponding decline in fertility.'

An outstanding feature in infant management, as in other aspects of Chinese domestic life, is a long-established tradition. This extends to the care given to children in the home. It has been considered in history (Garrison, 1923) that the status of the infant in society varies with that of the mother, and that therefore it is in the matriarchate in which the child is held in most esteem. Since Confucius the system in China has been maintained to be of the patriarchal type, but there is no question nowadays that considerable influence is exerted by women, especially by the lao-tai-tai (' old-great-great 'the master's mother, the matriarch). Before 200 B.C. there is said to have been no destruction of infants in China ; this is held to be accounted for by the existence then of mother authority. In other words, the Confucian idea of male sovereignty is associated with the abandonment or destruction of infants, especially the female, under the stress of famine or war, the child being regarded as a subject or chattel. Whilst this may be the case, it is a matter of common observation that in ordinary circumstances the Chinese treat their children kindly and well.

\section{REFERENCES}

Armand-Delille, P. F. (1935). J. State Med., 43, 683.

Bandoeng Conference (1937). Far East Conf. (League of Nations), 3, 76.

Buck (1938). Land Utilization in China. (Inst. of Pacific Relations Publications), Oxford, 1 393.

Feldman, W. M. (1920). Ante and Post Natal Child Physiology, London.

Garrison, F. H. (1923). Abt's. Paediatrics, Philadelphia, 1, 1.

Guy, R. (1936). Chinese med. J.. 50. 434.

Hutchison, R., and Mottram. V. H. (1936). Food and the Principles of Dietetics. 8th edition London.

King, (1936). Farmers of Forty Centuries, 291.

Larsen, N. P., Jones, M. R., and Pritchard, G. P. (1934). Amer. J. Dis. Child., 48, 1229.

Mellanby, E. (1937). Perspectives in Biochemistry, Ed. Needham and Green, Cambridge.

Nutritional Review of Natives of Nyasaland (1938), Zomba, Nyasaland, 6.

Platt, B. S. (1936). Chinese med. J.. 50, 410.

Still, G. F. (1931). History of Paediatrics. Oxford, 138.

White House Conference on Child Health and Protection (1932-1933). Report on Child Welfare (Physiology-Nutrition, 2 and 3). 